\title{
A Nomogram to Predict Distant Metastases After Multimodality Therapy for Patients With Localized Esophageal Cancer
}

\author{
Kazuki Sudo, MD ${ }^{a, *}$; Xuemei Wang, MS ${ }^{\mathrm{b}}$; Lianchun Xiao, MS ${ }^{\mathrm{b}}$; Roopma Wadhwa, MD, MPH ${ }^{\mathrm{a}}$; \\ Hironori Shiozaki, MDa; Elena Elimova, MD, MSca; David C. Rice, MDc; Jeffrey H. Lee, MD; \\ Brian Weston, MD; ${ }^{\mathrm{d}}$ Manoop S. Bhutani, MD ${ }^{\mathrm{d}}$; Adarsh Hiremath, MD; ${ }^{\mathrm{e}}$; Nikolaos Charalampakis, MD, PhD; \\ Ritsuko Komaki, MD; Mariela A. Blum, MDª; Stephen G. Swisher, MD; Dipen M. Maru, MD; \\ Heath D. Skinner, MD, PhD; ; Jeana L. Garris, PAC ${ }^{\text {a }}$ Jane E. Rogers, PharmD ${ }^{\text {h }}$, Wayne L. Hofstetter, $\mathrm{MD}^{\mathrm{c}}$; \\ and Jaffer A. Ajani, MD
}

\begin{abstract}
Background: Among patients with localized esophageal cancer (LEC), 35\% or more develop distant metastases (DM) as first relapse, most in the first 24 months after local therapy. Implementation of novel strategies may be possible if DM can be predicted reliably. We hypothesized that clinical variables could help generate a DM nomogram. Patients and Methods: Patients with LEC who completed multimodality therapy were analyzed. Various statistical methods were used, including multivariate analysis to generate a nomogram. A concordance index (c-index) was established and validated using the bootstrap method. Results: Among 629 patients analyzed (356 trimodality/ 273 bimodality), 36\% patients developed DM as first relapse. The median overall survival from DM was only 8.6 months (95\% Cl, 7.0-10.2). In a multivariate analysis, the variables associated with a higher risk for developing DM were poorly differentiated histology (hazard ratio $[H R], 1.76 ; P<.0001)$, baseline T3/T4 primary (HR, 3.07; $P=.0006)$, and baseline $N+L E C(H R, 2.01 ; P<.0001)$. Although variables associated with a lower risk for DM were age of 60 years or older (HR, $0.75 ; P=.04)$, squamous cell carcinoma (HR, $0.54 ; P=.013)$, and trimodality therapy $(\mathrm{HR}, 0.58 ; P=.0001)$, the bias-corrected c-index was 0.67 after 250 bootstrap resamples. Conclusions: Our nomogram identified patients with LEC who developed DM with a high probability. The model needs to be refined (tumor and blood biomarkers) and validated. This type of model will allow implementation of novel strategies in patients with LEC.
\end{abstract}

J Natl Compr Canc Netw 2016;14(2):173-178

\section{Background}

Among patients with localized esophageal cancer (LEC), $35 \%$ or more develop distant metastases (DM) as first relapse, most in the first 24 months after local therapy. ${ }^{1}$ Worldwide, yearly new cases of esophageal cancer are estimated to be 482,300 and yearly deaths are estimated to be 406,800 , and these include approximately 17,990 new cases and 15,210 deaths in the United States. ${ }^{2,3}$ For

\footnotetext{
From the Departments of a ${ }^{a}$ astrointestinal Medical Oncology; bBiostatistics; 'Thoracic and Cardiovascular Surgery; ' ${ }^{\mathrm{a}}$ Gastroenterology, Hepatology, and Nutrition; Internal Medicine; ${ }^{f}$ Pathology; ${ }^{9}$ Radiation Oncology; and hPharmacy Clinical Programs, The University of Texas MD Anderson Cancer Center, Houston, Texas.

*Current affiliations: Department of Gastrointestinal Medical Oncology, National Cancer Center Hospital, Tokyo, Japan; and Advanced Clinical Research of Cancer, Juntendo University Graduate School of Medicine, Tokyo, Japan.

Submitted December 16, 2014; accepted for publication December 2, 2015.
}

LEC, patients are offered preoperative chemotherapy, ${ }^{4}$ preoperative chemoradiation, ${ }^{5,6}$ or definitive chemoradiation ${ }^{7}$ depending on multiple factors (comorbidity, geographic distribution of cancer, practice preferences, and/or patient preferences). ${ }^{6}$

Approximately one-third or more patients with LEC who are offered various multimodal therapies subsequently develop DM, ${ }^{1,8}$ with the bulk of DM occurring within
The authors have disclosed that they have no financial interests, arrangements, affiliations, or commercial interests with the manufacturers of any products discussed in this article or their competitors. This work was supported by generous grants from the Caporella, Dallas, Sultan, Park, Smith, Frazier, Oaks, Vanstekelenberg, Planjery, and Cantu families; the Schecter Private Foundation, Rivercreek Foundation, Kevin Fund, Myer Fund, Dio Fund, and Milrod Fund; and multidisciplinary grants Supported in part by the National Cancer Institute (CA138671, CA172741, CA129926 to JAA) and grants from The University of Texas MD Anderson Cancer Center, Houston, TX, USA.

Correspondence: Jaffer A. Ajani, MD, Gastrointestinal Medical Oncology, The University of Texas MD Anderson Cancer Center, 1515 Holcombe Boulevard, Unit 0426, Houston, TX 77054. E-mail: jajani@mdanderson.org 
Sudo et al

2 years (more occurring in the first 12 months than in the second 12 months). ${ }^{1}$ The frequency of DM appears to correlate with higher postsurgical stage after trimodality therapy (TMT), ${ }^{1}$ and DM appears to be higher in patients assigned to bimodality therapy (BMT) than to TMT, because those who undergo BMT often have bulkier LECs. However, the worst-case scenario occurs when a patient undergoing TMT develops DM within 12 months of surgery. TMT can present considerable challenges to a patient's lifestyle, and one can argue that surgery should be avoided in patients with LEC who develop DM early in their clinical course. Another possible argument is that chemoradiation should be avoided in patients undergoing BMT who are likely to develop DM within months. Perhaps these patients can be palliated another way and the morbidity of chemoradiation can be avoided. This is an unmet need for this group of patients. Currently, tools that help identify these patients are not available. Nomograms provide much higher clinical value than individual independent variables in a multivariate analysis, because nomograms, by producing a single score per patient, have a higher clinical utility. ${ }^{9}$ A predictive nomogram can help to develop alternative strategies for patients with LEC who are at high risk for DM.

An ideal nomogram would incorporate clinical variables and possibly biomarkers (blood and tumor biomarkers). As a first step toward this goal, we hypothesized that a nomogram for DM could be established based on clinical variables using a large cohort of patients with LEC.

\section{Patients and Methods}

\section{Patient Population}

We analyzed a large number of patients with LEC from our prospectively maintained database in the Department of Gastrointestinal Medical Oncology at The University of Texas MD Anderson Cancer Center. Patients were identified between 2002 and 2013, had histologically confirmed LEC, and had completed BMT or TMT and were followed. All patients were fully staged with baseline endoscopic ultrasonography and CT and/or PET. Clinical staging was based on the 6th edition of the AJCC Cancer Staging Manual. ${ }^{10}$ The Institutional Review Board approved the study.

\section{Therapy}

Each patient was evaluated by multiple disciplines and then discussed in the multidisciplinary confer- ence (consisting of radiologists, gastroenterologists, thoracic surgeons, radiation oncologists, pathologists, nutritionists, geneticists [when appropriate], medical oncologists, and other caretakers) before proceeding with therapy. In addition to BMT or TMT, a fraction of patients had received induction chemotherapy (which has been shown not to influence the outcome of patients with LEC). ${ }^{11}$ Radiotherapy was given as 1.8 Gy per fraction for a total dose ranging from 45 to 50.4 Gy. At least 2 cytotoxic agents were routinely used. All patients received a fluoropyrimidine (intravenous or oral) plus either a platinum compound or a taxane with concurrent radiation. After chemoradiation, patients underwent restaging to include imaging and endoscopy. TMT-eligible patients proceeded to surgery. Patients were considered to have received TMT if surgery was performed within 6 months from the end of chemoradiation, and were considered to have received BMT if no surgery was performed or if surgery was performed more than 6 months after the completion of chemoradiation. No other selection criteria were implemented.

\section{Follow-up}

For patients undergoing BMT and TMT, we followed a uniform surveillance strategy as described for the patients undergoing TMT. ${ }^{12}$ Patients were monitored approximately every 3 months in the first 12 months, then every 6 months in the next 24 months, and then yearly until at least 5 years after treatment or until death. The survival follow-up was performed through our institution's tumor registry, electronic medical records, and/or the social security database.

\section{Statistical Analysis}

Patient characteristics were summarized using median (range) for continuous variables and frequency (percentage) for categorical variables. Fisher's exact test and Wilcoxon rank sum test were used to compare patient characteristics between TMT and BMT groups. Overall survival (OS) was defined as the interval between treatment start and the date of death due to any cause. Patients who were alive at the last follow-up date were censored at that time. Time to DM (TTDM) was defined as the interval between treatment start and the date of DM. Patients who were DM-free at the last follow-up date or died without DM were censored at the last followup date or death date, respectively. The probabilities of OS and being DM-free were estimated using the 
Kaplan-Meier method. Log rank tests and univariate Cox models were used to evaluate the association between patient characteristics and TTDM. Variables with a $P$ value less than 0.15 in the univariate analyses were included in the multivariate Cox proportional hazards regression model in order to identify those variables that were significantly associated with the risk of DM. The proportional hazards assumption was assessed using the method by Grambsch and Therneau. ${ }^{13}$ Using a backward model selection procedure, ${ }^{14}$ a final multivariate Cox model was identified. A nomogram for predicting the risk of DM was generated based on this final fitted Cox model. Its prediction accuracy was accessed using Harrell's concordance index (c-index). ${ }^{15}$ The model was internally validated using bootstrap resamples $(n=250)$ to calculate a bias-corrected c-index. Statistical analyses were performed using SAS 9.3 software (SAS Institute Inc., Cary, NC) and R software (http://www.r-project.org/). Statistical significance was defined as a $P$ value less than 0.05 .

\section{Results}

\section{Patient and Treatment Characteristics}

Between 2002 and 2013, we analyzed 629 patients. The median follow-up time was 37.2 months (interquartile range, $17.8-65.0$ months). Table 1 summarizes the patient characteristics. Of 629, 233 (37\%) received induction chemotherapy. The median radiation dose was 50.4 Gy (range, 45.0-66 Gy). A total of 356 (57\%) received TMT and 273 (43\%) received BMT.

\section{Time to Distant Metastases and Overall Survival}

Among the total 629 patients, 228 patients (36\%) developed DM, with 158 DMs occurring in the first year of the surveillance and 212 DMs occurring in 2 years. The median TTDM has not been reached in this cohort, and the estimated 2-year DM-free rate was $0.63(95 \% \mathrm{CI}, 0.59-0.67)$. In patients treated with BMT, 109 of 273 (40\%) had DM, and the estimated 2-year DM-free rate was 0.59 (95\% CI, 0.530.65). In the TMT group, 119 of 356 (33\%) developed DM and the estimated 2-year DM-free rate was 0.66 (95\% CI, 0.61-0.72).

A total of 304 of the 629 patients (48\%) died. The median OS time was 43.6 months $(95 \% \mathrm{CI}$, $37.8-52.4$ months). In the BMT group, 166 of 273 patients $(61 \%)$ died and the estimated median OS was 29.3 months (95\% CI, 25.1-39.5 months), whereas in the TMT group, 138 of 356 patients (39\%) died, and the median OS was 66.1 months (95\% CI, 48.3 months-not estimable). The median OS from DM was only 8.6 months (95\% CI, 7.0-10.2 months) for all 228 patients with DM.

\section{Univariate Analysis}

In the univariate analysis, TTDM was significantly associated with sex, primary site, histology, histologic grade, baseline $\mathrm{T}$, baseline $\mathrm{N}$, baseline stage, age, tumor size, and baseline standardized uptake value (SUV) (Table 2).

\section{Multivariate Analysis}

The multivariate Cox regression analysis (Table 3 ) found that age of 60 years or older (HR, $0.75 ; P=.04$ ), poorly differentiated histologic grade (HR, 1.76; $P<.0001)$, higher baseline T stage (T3/T4) (HR, 3.07; $P=.0006)$, baseline $\mathrm{N}+(\mathrm{HR}, 2.01 ; P<.0001)$, tumor histology being squamous cell carcinoma $(\mathrm{HR}, 0.54$; $P=.013)$, and receipt of TMT (HR, 0.58; $P=.0001)$ were independently associated with the risk of DM.

\section{Nomogram}

Figure 1 shows the nomogram developed to predict the risk of DM based on the fitted multivariate Cox regression model. The c-index based on the fitted model was 0.69 . We also performed internal validation using bootstrap resamples $(\mathrm{N}=250)$, and the bias-corrected c-index was 0.67 .

\section{Discussion}

Patients with LEC have a poor prognosis because many develop DM after local therapy is completed. In a large LEC population that underwent TMT, we previously reported that the rate of DM is higher among patients with a higher pathologic postchemoradiation stage. ${ }^{1}$ This observation is consistent with our previous report in which we documented that the more resistant the primary tumor is to chemoradiation, the more likely it has aggressive clinical features and the ability to develop DM..${ }^{16}$ In patients undergoing TMT, ${ }^{1}$ and also those undergoing BMT (unpublished data, 2013), DM occurs relatively early in the course of surveillance. This observation is of considerable importance, particularly for those undergoing TMT. The scenario one would not want to observe is one in which a patient completes TMT but develops DM within months of surgery. The prognosis of such patients is extremely poor and their survival is short. We should strive to identify patients, particularly those undergoing TMT, who are at risk 
Sudo et al

\section{Table 1. Patient Characteristics}

\begin{tabular}{|c|c|c|c|c|c|c|c|}
\hline \multicolumn{2}{|l|}{ Covariate } & \multicolumn{2}{|c|}{$\begin{array}{l}\text { Total } \\
(\mathrm{N}=629)\end{array}$} & \multicolumn{2}{|c|}{$\begin{array}{l}\text { TMT } \\
(\mathrm{N}=356)\end{array}$} & $\begin{array}{l}\text { BMT } \\
(\mathrm{N}=273)\end{array}$ & $P$ Value \\
\hline \multicolumn{8}{|l|}{ Age, y } \\
\hline & Median & \multicolumn{2}{|l|}{63} & \multicolumn{2}{|l|}{60} & 68 & $<.0001$ \\
\hline & Range & \multicolumn{2}{|c|}{$20-91$} & \multicolumn{2}{|c|}{$27-78$} & 20-91 & \\
\hline \multicolumn{8}{|l|}{ Sex, $\mathrm{n}(\%)$} \\
\hline & Male & 554 & $(88.1)$ & 317 & $(89.0)$ & $237 \quad(86.8)$ & .392 \\
\hline & Female & 75 & (11.9) & 39 & $(11.0)$ & $36 \quad(13.2)$ & \\
\hline \multicolumn{8}{|c|}{ Race, n (\%) } \\
\hline & White & 562 & (89.3) & 326 & $(91.6)$ & $236(86.4)$ & .0499 \\
\hline & Non-White & 67 & $(10.7)$ & 30 & $(8.4)$ & $37 \quad(13.6)$ & \\
\hline \multicolumn{8}{|c|}{ Primary site, $\mathrm{n}(\%)$} \\
\hline & Esophagus & 95 & (15.1) & 32 & $(9.0)$ & $63 \quad(23.1)$ & $<.0001$ \\
\hline & Type Ia & 313 & $(49.8)$ & 194 & $(54.5)$ & $119(43.6)$ & \\
\hline & Type II $^{\mathrm{a}}$ & 221 & (35.1) & 130 & $(36.5)$ & $91 \quad$ (33.3) & \\
\hline \multicolumn{8}{|c|}{ Histology, n (\%) } \\
\hline & Adenocarcinoma & 550 & (87.4) & 334 & $(93.8)$ & $216(79.1)$ & $<.0001$ \\
\hline & SCC & 79 & $(12.6)$ & 22 & $(6.2)$ & $57 \quad(20.9)$ & \\
\hline \multicolumn{8}{|c|}{ Histologic grade, n (\%) } \\
\hline & Well/Moderate & 298 & $(47.4)$ & 171 & $(48.0)$ & $127(46.5)$ & .747 \\
\hline & Poorly & 331 & $(52.6)$ & 185 & $(52.0)$ & $146(53.5)$ & \\
\hline \multicolumn{8}{|c|}{ Baseline T stage, n (\%) } \\
\hline & $\mathrm{T} 1$ & 11 & $(1.7)$ & 2 & $(0.6)$ & (3.3) & .005 \\
\hline & $\mathrm{T} 2$ & 64 & $(10.2)$ & 40 & $(11.2)$ & $24 \quad(8.8)$ & \\
\hline & T3 & 537 & (85.4) & 309 & $(86.8)$ & $228(83.5)$ & \\
\hline & T4 & 17 & $(2.7)$ & 5 & (1.4) & $12 \quad(4.4)$ & \\
\hline \multicolumn{8}{|c|}{ Baseline $\mathrm{N}$ stage, $\mathrm{n}(\%)$} \\
\hline & NO & 221 & (35.1) & 135 & (37.9) & $86 \quad(31.5)$ & .109 \\
\hline & N1 & 408 & (64.9) & 221 & $(62.1)$ & $187(68.5)$ & \\
\hline \multicolumn{8}{|c|}{ Baseline M stage, n (\%) } \\
\hline & Mo & 614 & $(97.6)$ & 347 & (97.5) & $267 \quad(97.8)$ & 1.00 \\
\hline & M1a & 15 & $(2.4)$ & 9 & (2.5) & $(2.2)$ & \\
\hline \multicolumn{8}{|c|}{ Baseline stage, $\mathrm{n}(\%)$} \\
\hline & Stage I & 10 & $(1.6)$ & 2 & $(0.6)$ & (2.9) & .028 \\
\hline & Stage II & 236 & (37.5) & 146 & $(41.0)$ & $90 \quad(33.0)$ & \\
\hline & Stage III & 368 & $(58.5)$ & 199 & (55.9) & $169(61.9)$ & \\
\hline & Stage IVA & 15 & $(2.4)$ & 9 & (2.5) & $(2.2)$ & \\
\hline \multicolumn{8}{|c|}{ Induction chemotherapy, n (\%) } \\
\hline & Yes & 233 & $(37.0)$ & 147 & $(41.3)$ & $86 \quad(31.5)$ & .013 \\
\hline & No & 396 & $(63.0)$ & 209 & $(58.7)$ & $187(68.5)$ & \\
\hline
\end{tabular}

Abbreviations: BMT, bimodality therapy; SCC, squamous cell carcinoma; TMT, trimodality therapy. aEsophagogastric junction cancer was classified according to the Siewert classification.

for DM shortly after local therapy. Currently, we lack any method to identify such patients, but if we could identify them, one strategy would be to delay their surgery and closely monitor them for DM. Another possible strategy would be to avoid chemoradiation in high-risk patients, because chemoradiation is associated with considerable morbidity.
Our current nomogram is far from ready for clinical implementation and should be considered only as the first step in a challenging process. The c-index based on the fitted model was 0.69 and the bootstrap bias-corrected c-index was 0.67 , which were moderately good results in terms of predictive accuracy. Our nomogram will require independent validation 
Nomogram to Predict Esophageal Metastases

\begin{tabular}{|c|c|c|c|c|c|c|}
\hline Variable & Level & $\mathbf{N}$ & $\begin{array}{l}\mathrm{N} \text { of } \\
\mathrm{DM}\end{array}$ & $\begin{array}{l}\text { Median Time } \\
\text { to DM } \\
(95 \% \mathrm{Cl})\end{array}$ & $\begin{array}{l}\text { 2-Year } \\
\text { DM-Free Rate } \\
(95 \% \mathrm{Cl})\end{array}$ & $P$ Value \\
\hline \multicolumn{7}{|l|}{ Age, y } \\
\hline & $<60$ & 237 & 98 & NA $(31.5, N A)$ & $0.61(0.54,0.68)$ & .08 \\
\hline & $\geq 60$ & 392 & 130 & NA (NA, NA) & $0.64(0.59,0.7)$ & \\
\hline \multicolumn{7}{|l|}{ Sex } \\
\hline & Female & 75 & 15 & NA (NA, NA) & $0.78(0.68,0.89)$ & .007 \\
\hline & Male & 554 & 213 & NA (NA, NA) & $0.61(0.57,0.65)$ & \\
\hline \multicolumn{7}{|l|}{ Location } \\
\hline & AEG 1 & 313 & 130 & NA $(29.4, N A)$ & $0.57(0.51,0.63)$ & .04 \\
\hline & AEG 2 & 221 & 68 & NA (NA, NA) & $0.7(0.64,0.77)$ & \\
\hline & Esophagus & 95 & 30 & NA (NA, NA) & $0.66(0.57,0.78)$ & \\
\hline \multicolumn{7}{|c|}{ Baseline T stage } \\
\hline & $\mathrm{T} 1$ & 11 & 0 & NA (NA, NA) & $1(1,1)$ & $<.0001$ \\
\hline & $\mathrm{T} 2$ & 64 & 10 & NA (NA, NA) & $0.89(0.81,0.97)$ & \\
\hline & T3 & 537 & 209 & NA (NA, NA) & $0.59(0.55,0.64)$ & \\
\hline & T4 & 17 & 9 & $10.81(9.4, N A)$ & $0.4(0.2,0.77)$ & \\
\hline \multicolumn{7}{|c|}{ Baseline T stage } \\
\hline & $\mathrm{T} 1 / \mathrm{T} 2$ & 75 & 10 & NA (NA, NA) & $0.9(0.83,0.97)$ & $<.0001$ \\
\hline & $\mathrm{T} 3 / \mathrm{T} 4$ & 554 & 218 & NA $(51.35, N A)$ & $0.59(0.55,0.63)$ & \\
\hline \multicolumn{7}{|c|}{ Baseline N stage } \\
\hline & NO & 221 & 51 & NA (NA, NA) & $0.77(0.71,0.83)$ & $<.0001$ \\
\hline & N1 & 408 & 177 & $47.37(28.06, N A)$ & $0.55(0.5,0.61)$ & \\
\hline \multicolumn{7}{|c|}{ Baseline M stage } \\
\hline & MO & 614 & 220 & NA (NA, NA) & $0.63(0.59,0.67)$ & .22 \\
\hline & M1a & 15 & 8 & $29.4(11.73, \mathrm{NA})$ & $0.51(0.30,0.86)$ & \\
\hline \multicolumn{7}{|c|}{ Baseline stage } \\
\hline & I & 10 & 0 & NA (NA, NA) & $1(1,1)$ & $<.0001$ \\
\hline & II & 236 & 56 & NA (NA, NA) & $0.77(0.72,0.83)$ & \\
\hline & III & 368 & 164 & $31.31(19.58, N A)$ & $0.53(0.47,0.59)$ & \\
\hline & IVA & 15 & 8 & $29.4(11.73, \mathrm{NA})$ & $0.51(0.3,0.86)$ & \\
\hline \multicolumn{7}{|c|}{ Stage III or IV } \\
\hline & No & 261 & 64 & NA (NA, NA) & $0.76(0.71,0.82)$ & $<.0001$ \\
\hline & Yes & 368 & 164 & $31.31(19.58, N A)$ & $0.53(0.47,0.59)$ & \\
\hline \multicolumn{7}{|c|}{ Tumor grade } \\
\hline & Poorly differentiated & 331 & 147 & $53.84(18.69, \mathrm{NA})$ & $0.54(0.48,0.6)$ & $<.0001$ \\
\hline & $\begin{array}{l}\text { Well-moderately } \\
\text { differentiated }\end{array}$ & 298 & 81 & NA (NA, NA) & $0.73(0.68,0.79)$ & \\
\hline \multicolumn{7}{|c|}{ Tumor histology } \\
\hline & Adenocarcinoma & 550 & 209 & NA (NA, NA) & $0.62(0.58,0.66)$ & .10 \\
\hline & Squamous cell cancer & 79 & 19 & NA (NA, NA) & $0.72(0.61,0.84)$ & \\
\hline \multicolumn{7}{|c|}{ Induction chemotherapy } \\
\hline & No & 396 & 135 & NA (NA, NA) & $0.64(0.59,0.69)$ & .41 \\
\hline & Yes & 233 & 93 & NA $(35.71, N A)$ & $0.61(0.55,0.68)$ & \\
\hline \multicolumn{7}{|c|}{ Tumor length $(\mathrm{cm})$} \\
\hline & $<5$ & 252 & 66 & NA (NA, NA) & $0.74(0.68,0.8)$ & $<.0001$ \\
\hline & $\geq 5$ & 350 & 153 & NA $(19.97, N A)$ & $0.55(0.49,0.61)$ & \\
\hline \multicolumn{7}{|c|}{ Baseline PET-SUV } \\
\hline & $\leq 10$ & 271 & 85 & NA (NA, NA) & $0.7(0.65,0.76)$ & .007 \\
\hline & $>10$ & 296 & 118 & NA $(31.27, N A)$ & $0.57(0.51,0.63)$ & \\
\hline \multicolumn{7}{|c|}{ Treatment } \\
\hline & BMT & 273 & 109 & NA $(53.84, N A)$ & $0.59(0.53,0.65)$ & .007 \\
\hline & TMT & 356 & 119 & NA (NA, NA) & $0.66(0.61,0.72)$ & \\
\hline
\end{tabular}

Abbreviations: AEG, adenocarcinoma involving the esophagogastric junction; BMT, bimodality therapy; DM, distant metastases; NA, not applicable; PET-SUV, standardized uptake value of positron emission tomography; TMT, trimodality therapy. 
Sudo et al

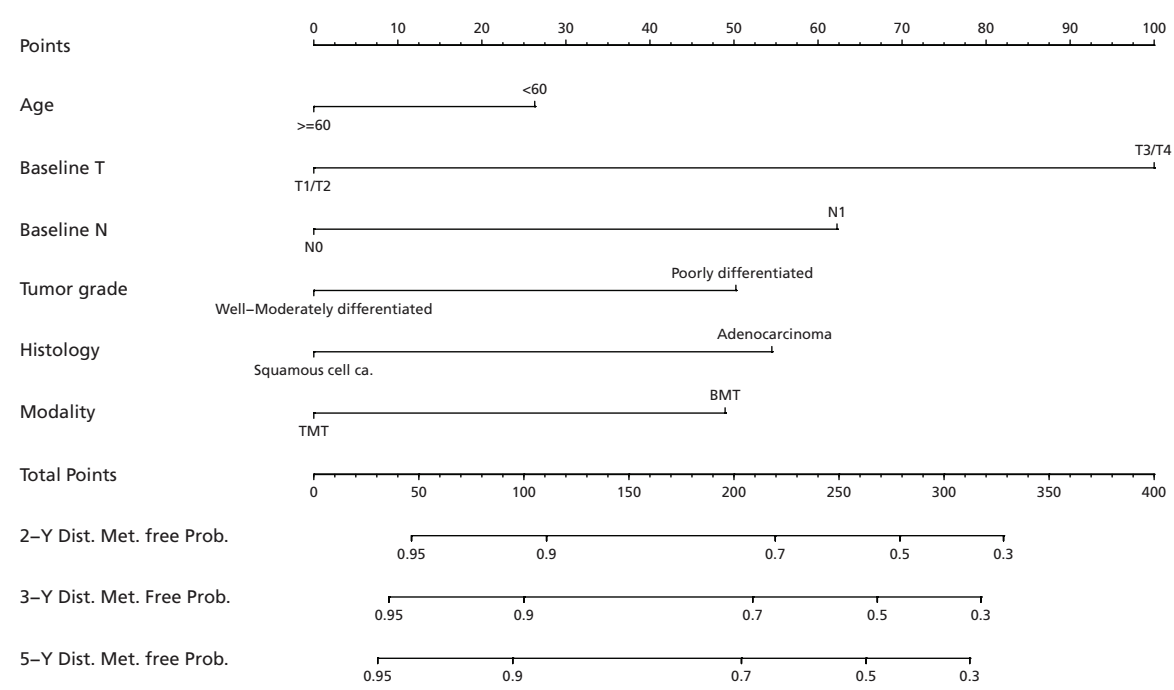

Figure 1. Nomogram for predicting distant metastases.

Abbreviations: BMT, bimodality therapy; Ca, cancer; Dist. Met. free Prob., distant metastasis-free probability; TMT, trimodality therapy.

and further refinement, perhaps by the addition of tumor or blood biomarkers to improve its predictive accuracy. Acknowledging that surgery contributes immensely to the cure rate of patients with esophageal cancer, ${ }^{17,18}$ one would like to have a high level of predictive accuracy from the model to avoid undertreatment of patients who are likely to benefit from surgery.

This study's weaknesses are its retrospective nature and that it represents a single-institution analysis. The strength of our analysis is that it is the first demonstration that a nomogram based on clinical parameters can be established and that it is ready to be validated and refined.

\begin{tabular}{|c|c|c|c|}
\hline Covariate & $P$ Value & HR & $95 \% \mathrm{Cl}$ \\
\hline Age $\geq 60$ y $(v s<60)$ & .04 & 0.75 & $0.56,0.99$ \\
\hline $\begin{array}{l}\text { Poor differentiated } \\
\text { (vs well/moderate) }\end{array}$ & $<.0001$ & 1.76 & $1.34-2.31$ \\
\hline $\begin{array}{l}\text { Baseline T3/T4 } \\
\text { (vs T1/T2) }\end{array}$ & .0006 & 3.07 & $1.62-5.81$ \\
\hline Baseline $\mathrm{N}+$ (vs N0) & $<.0001$ & 2.01 & $1.46-2.76$ \\
\hline $\begin{array}{l}\text { Tumor histology } \\
\text { (squamous } \\
\text { cell cancer vs } \\
\text { adenocarcinoma) }\end{array}$ & 01 & 0.54 & $0.34-0.88$ \\
\hline $\begin{array}{l}\text { Treatment } \\
\text { (TMT vs BMT) }\end{array}$ & .0001 & 0.58 & $0.44-0.77$ \\
\hline
\end{tabular}

Abbreviations: BMT, bimodality therapy; DM, distant metastases; HR, hazard ratio; TMT, trimodality therapy.

\section{Conclusions}

Our data suggest that younger men with baseline T3/4, $\mathrm{N}+$, poorly differentiated esophageal cancer with adenocarcinoma who are treated with BMT/TMT are at high risk for developing DM. The nomogram presented can become useful for avoiding or delaying surgery in these patients if it can be validated and further refined.

\section{References}

1. Taketa $T$, Sudo $K$, Correa AM, et al. Post chemoradiation surgical pathology stage can customize the surveillance strategy in patients with esophageal adenocarcinoma. J Natl Compr Canc Netw 2014;12:1139-1144.

2. Siegel R, Naishadham D, Jemal A. Cancer statistics, 2012. CA Cancer J Clin 2012;62:10-29.

3. Jemal A, Bray F, Center MM, et al. Global cancer statistics. CA Cancer J Clin 2011;61:69-90.

4. Allum WH, Stenning SP, Bancewicz J, et al. Long-term results of a randomized trial of surgery with or without preoperative chemotherapy in esophageal cancer. J Clin Oncol 2009;27:5062-5067.

5. van Hagen P, Hulshof MC, van Lanschot JJ, et al. Preoperative chemoradiotherapy for esophageal or junctional cancer. $N$ Engl J Med 2012;366:2074-2084.

6. Ajani JA, Barthel JS, Bentrem DJ, et al. Esophageal and esophagogastric junction cancers. J Natl Compr Canc Netw 2011;9:830-887.

7. Cooper JS, Guo MD, Herskovic A, et al. Chemoradiotherapy of locally advanced esophageal cancer: long-term follow-up of a prospective randomized trial (RTOG 85-01). Radiation Therapy Oncology Group. JAMA 1999;281:1623-1627.

8. Shiozaki H, Sudo K, Xiao L, et al. Distribution and timing of distant metastasis after local therapy in a large cohort of patients with esophageal and esophagogastric junction cancer. Oncology 2014;86:336-339.

9. Shariat SF, Karakiewicz PI, Suardi N, et al. Comparison of nomograms with other methods for predicting outcomes in prostate cancer: a critical analysis of the literature. Clin Cancer Res 2008;14:4400-4407.

10. Greene FL, Page DL, Fleming ID, et al, eds. AJCC Cancer Staging Manual. 6th ed. New York, NY: Springer-Verlag; 2002.

11. Ajani JA, Xiao L, Roth JA, et al. A phase II randomized trial of induction chemotherapy versus no induction chemotherapy followed by preoperative chemoradiation in patients with esophageal cancer. Ann Oncol 2013;24:28442849. 
12. Sudo $K$, Taketa T, Correa AM, et al. Locoregional failure rate after preoperative chemoradiation of esophageal adenocarcinoma and the outcomes of salvage strategies. J Clin Oncol 2013;31:4306-4310.

13. Grambsch $P$, Therneau T. Proportional hazards tests and diagnostics based on weighted residuals. Biometrika 1994;81:515-526.

14. Harrell FE Jr, Lee KL, Mark DB. Multivariable prognostic models: issues in developing models, evaluating assumptions and adequacy, and measuring and reducing errors. Stat Med 1996;15:361-387.

15. Harrell FE. Regression modeling strategies: with applications to linear models, logistic regression, and survival analysis. New York, NY: Springer; 2001.
16. Rohatgi PR, Swisher SG, Correa AM, et al. Failure patterns correlate with the proportion of residual carcinoma after preoperative chemoradiotherapy for carcinoma of the esophagus. Cancer 2005;104:1349-1355.

17. Patnana SV, Murthy SB, Xiao L, et al. Critical role of surgery in patients with gastroesophageal carcinoma with a poor prognosis after chemoradiation as defined by positron emission tomography. Cancer 2010;116:4487-4494.

18. Murphy CC, Correa AM, Ajani JA, et al. Surgery is an essential component of multimodality therapy for patients with locally advanced esophageal adenocarcinoma. J Gastrointest Surg 2013;17:1359-1369. 